\title{
Ensino-aprendizagem de Matemática via Resolução de Problemas: análise do processo de resolução de problemas de licenciandos em formação inicial ${ }^{1}$
}

\author{
Teaching-learning of Mathematics via Problem Solving: analysis of the problem solving \\ process of undergraduates in initial formation
}

\begin{abstract}
Enseñanza-aprendizaje de matemáticas vía resolución de problemas: análisis del proceso de resolución de problemas de los estudiantes de pregrado en formación inicial
\end{abstract}

Luiz Otavio Rodrigues Mendes²

Universidade Estadual de Maringá (UEM), Maringá, PR, Brasil https://orcid.org/0000-0002-3160-8532, 9 http://lattes.cnpq.br/8661805143319375

Marcelo Carlos de Proença ${ }^{3}$

Universidade Estadual de Maringá (UEM), Maringá, PR, Brasil https://orcid.org/0000-0002-6496-4912, O http://lattes.cnpq.br/9198626057262085

Ana Lucia Pereira ${ }^{4}$

Universidade Estadual de Ponta Grossa (UEPG), Ponta Grossa, PR, Brasil https://orcid.org/0000-0003-0970-260X, 9 http://lattes.cnpq.br/4341211442617752 João Alessandro da Luz
Universidade Estadual de Maringá (UEM), Maringá, PR, Brasil
https://orcid.org/0000-0002-9717-110X, 9 http://lattes.cnpq.br/1315361025166246

Resumo: O presente trabalho tem como objetivo analisar o processo de Resolução de Problemas de licenciandos em formação inicial no contexto formativo do Ensino-Aprendizagem de Matemática via Resolução de Problemas (EAMvRP). Para tanto, tratamos da abordagem do EAMvRP com 18 licenciandos de uma universidade pública do norte do Paraná. As aulas foram gravadas e transcritas e, junto com as resoluções realizadas pelos licenciandos, foram analisadas qualitativamente de forma descritiva. A análise procedeu por meio de uma sintetização das etapas de Resolução de Problemas de Proença (2018). Os principais resultados revelam que na etapa de representação, compreender adequadamente os conhecimentos semânticos, linguísticos e esquemáticos favorecem a identificação de informações supérfluas ao problema. Percebemos que na etapa de planejamento, a utilização da simbologia matemática colaborou para justificar a resolução dos grupos. Na etapa de execução, todos os grupos apresentaram ter um tipo de mente viso-pictórico quando utilizaram de desenhos para desenvolver suas resoluções. Por fim, na última etapa - monitoramento -, identificamos que apenas uma das quatro resoluções que foram analisadas desenvolveu esta etapa de forma satisfatória apresentando uma resposta final ao problema. Assim, podemos concluir que ao se desenvolver o EAMvRP levando-se em consideração as etapas de

\footnotetext{
1 Artigo apresentado no I Simpósio de Resolução de Problemas na Educação Matemática (I SiRPEM), da Universidade Estadual de Maringá, Maringá, Paraná, realizado nos dias 29 e 30 de julho de 2021.

2 Currículo sucinto: Licenciado em Matemática pela Universidade Estadual de Ponta Grossa (UEPG), mestre em Ensino de Ciências e Educação Matemática (UEPG) e doutorando em Educação para a Ciência e a Matemática pela Universidade Estadual de Maringá (UEM). Contribuição de autoria: Administração do Projeto, Curadoria de Dados, Escrita - Primeira Redação, Investigação e Visualização. Contato: mendesluizotavio@hotmail.com.

3 Currículo sucinto: Licenciado em Matemática, mestre e doutor pela Universidade Estadual Paulista "Julio de Mesquita Filho" (UNESP). Contribuição de autoria: Análise Formal, Escrita - Revisão e Edição, Investigação, Validação e Visualização. Contato: mcproenca@uem.br.

${ }^{4}$ Currículo sucinto: Licenciada em Matemática pela Universidade Estadual do Norte do Paraná (UENP), mestre e doutora em Ensino de Ciências e Educação Matemática pela Universidade Estadual de Londrina (UEL). Contribuição de autoria: Conceituação, Escrita Revisão e Edição, Validação e Visualização. Contato: ana.lucia.pereira.173@gmail.com.

${ }^{5}$ Currículo sucinto: Licenciando em Matemática pela Universidade Estadual do Paraná (UNESPAR), mestre em Matemática pela Universidade Estadual de Maringá (UEM) e doutorando em Educação para a Ciência e a Matemática (UEM). Contribuição de autoria: Escrita - Revisão e Edição, Metodologia e Visualização. Contato: joaoalessandro.luz@gmail.com.
} 
resolução de Proença (2018), o processo se torna muito mais rico, mais interessante, colabora na identificação das possíveis dificuldades dos estudantes e, consequentemente, favorece o desenvolvimento de um ensino de Matemática profícuo.

Palavras-chave: problema como ponto de partida; solução de problemas; dificuldades.

Abstract: This work aims to analyze the Problem Solving process of undergraduates in initial formation in the formative context of Teaching-Learning of Mathematics via Problem Solving (EAMvRP). Therefore, we dealt with the EAMvRP approach with 18 graduates from a public university in northern Paraná. The classes were recorded and transcribed and, together with the resolutions made by the undergraduates, they were qualitatively analyzed in a descriptive way. The analysis proceeded through a synthesis of the steps of Problem Solving in Proença (2018). The main results reveal that in the representation stage, properly understanding the semantic, linguistic and schematic knowledge favors the identification of information superfluous to the problem. We noticed that in the planning stage, the use of mathematical symbology collaborated to justify the resolution of the groups. In the execution stage, all groups had a visual-pictorial type of mind when they used drawings to develop their resolutions. Finally, in the last step - monitoring -, we identified that only one of the four resolutions that were analyzed developed this step satisfactorily, presenting a final answer to the problem. Thus, we can conclude that when developing the EAMvRP taking into account the steps of resolution of Proença (2018), the process becomes much richer, more interesting, collaborates in the identification of possible difficulties for students and, consequently, favors the development of a fruitful teaching of Mathematics.

Keywords: problem as a starting point; problems solution; difficulties.

Resumen: Este trabajo tiene como objetivo analizar el proceso de Resolución de Problemas de los estudiantes de pregrado en formación inicial en el contexto formativo de la Enseñanza-Aprendizaje de las Matemáticas vía Resolución de Problemas (EAMvRP). Por tanto, abordamos el enfoque EAMvRP con 18 egresados de una universidad pública del norte de Paraná. Las clases fueron grabadas y transcritas y, junto con las resoluciones tomadas por los estudiantes, fueron analizadas cualitativamente de manera descriptiva El análisis procedió a través de una síntesis de los pasos de la Resolución de Problemas en Proença (2018). Los principales resultados revelan que en la etapa de representación a comprensión adecuada del conocimiento semántico, lingüístico y esquemático favorece la identificación de información superflua al problema. Notamos que en la etapa de planificación el uso de simbología matemática colaboró para justificar la resolución de los grupos. En la etapa de ejecución, todos los grupos demostraron tener una mentalidad visual-pictórica cuando utilizaron dibujos para desarrollar sus resoluciones. Finalmente, en el último paso - monitoreo -, identificamos que solo una de las cuatro resoluciones analizadas desarrolló satisfactoriamente este paso, presentando una respuesta final al problema. Así, podemos concluir que al desarrollar el EAMvRP teniendo en cuenta los pasos de resolución de Proença (2018), el proceso se vuelve mucho más rico, más interesante, colabora en la identificación de posibles dificultades para los estudiantes $y$, en consecuencia, favorece el desarrollo de una proficua nseñanza de las matemáticas.

Palabras clave: problema como punto de partida; solución de problemas; dificultades.

Data de submissão: 20 de setembro de 2021

Data de aprovação: 22 de outubro de 2021

\section{Introdução}

A Matemática está presente em todas as etapas da Educação Básica e, com sua formalidade de conceitos, abstração e complexidade, intriga diversos pesquisadores sobre como desenvolver o seu processo de ensino. Os Parâmetros Curriculares Nacionais (BRASIL,1998) indicam que o ensino de um conteúdo matemático deve abordar um problema como ponto de partida. Essa é a perspectiva considerada mais adequada para se trabalhar com a Resolução de 
Problemas (ONUCHIC, ALLEVATO, 2011, ONUCHIC et al., 2014, PROENÇA, 2018, MENDES; AFONSO; PROENÇA, 2020).

A realização de processos de ensino sob esta perspectiva vem sendo elaborada a luz do processo de Ensino-Aprendizagem de Matemática via Resolução de Problemas (EAMvRP) de Proença (2018), compreendido em cinco ações, a saber: i) escolha do problema; ii) introdução do problema; iii) auxílio aos alunos durante a resolução; iv) discussão das estratégias dos alunos; e v) articulação das estratégias dos alunos ao conteúdo. Este processo de ensino vem sendo abordado desde o Ensino Fundamental, Ensino Médio, bem como no Ensino Superior, sejam em cursos de formação inicial ou continuada (MENDES; PROENÇA, 2020, PROENÇA, 2019a, SOUZA; PROENÇA, 2019).

Em profundidade, as ações de Proença (2018) além de favorecerem o trabalho no uso do problema como ponto de partida para o ensino de um conteúdo novo, também favorecem uma avaliação da aprendizagem e, em específico, do processo de resolução dos alunos. $O$ autor destaca que em sua terceira e quarta ação, uma avaliação deve ser desenvolvida pelo professor em termos de etapas de Resolução de Problemas. Para tal, na literatura, há várias referências que ajudam a fazer essa avaliação como, por exemplo, as perspectivas de etapas de Resolução de Problemas de Wallas (1926), Polya (1994) e Sternberg (2000).

Assim, no caso de Proença (2018, p. 46), o autor apresenta quatro etapas de Resolução de Problemas, a saber: representação, planejamento, execução e monitoramento. Tais etapas advém de uma complexa relação e estruturação das etapas de Brito (2006) a partir dos conhecimentos matemáticos de Mayer (1985) e das habilidades matemáticas de Krutetskii (1976). Ao observarmos pesquisas que abordaram o EAMvRP, identificamos que as etapas de Resolução de Problemas não foram analisadas em maior profundidade (MENDES; AFONSO; PROENÇA, 2020, MENDES; PROENÇA, 2020).

À vista disso, e tomando como certo que a formação inicial de professores é o momento para tratar de abordagens como o EAMvRP, bem como sobre o processo de Resolução de Problemas, este trabalho tem como objetivo analisar o processo de Resolução de Problemas de licenciandos em formação inicial no contexto formativo do Ensino-Aprendizagem de Matemática via Resolução de Problemas.

Para tanto, este estudo está estruturado da seguinte forma: após esta introdução, apresentamos o embasamento teórico referente ao EAMvRP e as etapas de Resolução de Problemas na Matemática de Proença (2018). Por conseguinte, expomos os procedimentos metodológicos do desenvolvimento do estudo. Por fim, a análise dos dados e as considerações finais são apresentadas. 


\section{Embasamento Teórico}

Proença (2018) propôs o que denomina de Ensino-Aprendizagem de Matemática via Resolução de Problemas, EAMvRP, que se constitui em cinco ações. A primeira é a escolha do problema, desenvolvida fora da sala de aula em um momento de preparação da aula. Um possível problema deve ser escolhido, de forma que este pode ser elaborado, reelaborado ou utilizado na íntegra. Proença (2018) considera que nesta ação, os seguintes objetivos devem ser desenvolvidos:

Direcionar os alunos a utilizar conceitos, princípios e procedimentos matemáticos aprendidos anteriormente durante a escolarização para resolver a situação de matemática; [...] Levar os alunos a construir o conteúdo/conceito/assunto a ser introduzido; [...] Propiciar condições para que os alunos estabeleçam relações entre os conhecimentos matemáticos utilizados e entre eles e o novo conhecimento. (PROENÇA, 2018, p. 46).

Nesta perspectiva, os conhecimentos prévios dos alunos devem ser valorizados. Isso implica na necessidade de escolher situações problemas que tenham, se possível, mais de uma forma de resolver, ou seja, mais de uma estratégia de resolução. Quanto a estas estratégias, Proença (2018) reforça a importância de o professor conhecê-las, tais como: organização dos dados, tentativa e erro, realizando uma simulação, trabalhando ao inverso, raciocínio lógico, etc. "A intenção é evitar um trabalho que não leve em consideração o que os alunos fazem pelo fato de o próprio professor desconhecer um conceito ou procedimento empregado como estratégia [...]" Proença (2018, p. 47).

A segunda ação, introdução do problema, corresponde ao momento em que o professor estará em sala de aula com seus alunos. Para tanto, deve dividir os alunos em grupos e Ihes apresentar a situação de matemática. Proença (2018) destaca que um ponto importante é que o professor não deve comentar sobre qual conteúdo está sendo trabalhado, no intuito de que os conhecimentos prévios sejam valorizados. Por fim, os alunos devem buscar resolver as situações da forma que acharem melhor.

O auxílio aos alunos durante a resolução corresponde à terceira ação, quando os alunos já começaram a resolver a situação de matemática e, pelas dificuldades encontradas para propor um caminho de resolução, esta se torna um problema para eles. Nesse processo, o professor desenvolve um trabalho de mediador, ou seja, observa, incentiva e direciona a aprendizagem. Para tanto, as possíveis dúvidas quanto à interpretação do problema, referente, por exemplo, aos termos matemáticos, devem ser foco de apoio por parte do professor. Desta forma, avaliar em termos de etapas de resolução pode ajudar o professor a identificar as possíveis dificuldades dos alunos. 
Outrossim, o uso inadequado de uma estratégia também deve ser observado e, caso algum grupo não consiga avançar na resolução, Proença (2018) comenta que o professor deve direcionar o grupo a uma estratégia que foi previamente estruturada na primeira ação. No entanto, esse direcionamento não deve ser no sentido de dar respostas prontas ao grupo.

Após todos os grupos terem resolvido o problema, ocorre a quarta ação, discussão das estratégias dos alunos ao conteúdo, momento esse de socialização das respostas. Para tanto, o professor deve pedir que um integrante de cada grupo vá ao quadro e apresente o que o grupo encontrou. Esse processo favorece um interessante momento de reflexão e discussão entre a turma.

O professor também deve estar atento, uma vez que deve apontar possíveis dificuldades e equívocos dos alunos. Com ênfase, estas dificuldades devem ser analisadas na perspectiva das etapas de Resolução de Problemas - representação, planejamento, execução e monitoramento. Desta forma, é possível levá-los a perceber a racionalidade de suas resoluções e a sintetizar o conteúdo (PROENÇA, 2018).

Por fim, a ação de articulação das estratégias dos alunos ao conteúdo é desenvolvida, quando o professor escolhe uma das estratégias dos alunos ou a sua própria que foi desenvolvida previamente, para articular os pontos centrais ao conteúdo/conceito/assunto que se quer ensinar. Caso isso não seja possível, Proença (2018) destaca que a apresentação da resolução pode ser feita de forma direta.

Ao observarmos a condução do EAMvRP, na terceira e na quarta ação, evidenciamos que uma avaliação do processo de ensino ocorre em termos de etapas de resolução. Dentre as possibilidades de etapas de resolução que podem ser utilizadas nessa avaliação, destacamos as quatro etapas de Proença (2018), a saber: representação, planejamento, execução e monitoramento. $\mathrm{O}$ autor apresenta suas etapas em seu livro de forma descritiva, no entanto, para posteriormente sermos mais objetivos em nosso processo de análise dos dados, apresentamos na Tabela 1 a descrição das etapas de forma pontual, bem como a análise que deve ser feita referente a cada descrição.

Compreendemos, da Tabela 1, que, além de apresentarmos as etapas de resolução de Proença (2018), descrever como podem ser analisadas ajuda a favorecer o processo de avaliação que deve ser feito pelo professor. Nessa perspectiva, Luz e Proença (2019) investigaram as dificuldades de 34 alunos do Ensino Médio sobre geometria espacial sobre questões do Exame Nacional do Ensino Médio. Os autores identificaram dificuldades principalmente nas etapas de representação referentes à interpretação e compreensão dos enunciados e na etapa de execução, referente à falta de conhecimentos sobre o conteúdo. Tais dificuldades já haviam sido evidenciadas também no trabalho de Araujo (2015) que trabalhou com o Ensino Fundamental. 
Tabela 1 - Síntese das etapas de Resolução de Problemas de Proença (2018)

\begin{tabular}{|c|c|c|}
\hline Etapa & $\begin{array}{l}\text { Descrição de Proença } \\
\text { (2018) }\end{array}$ & Análise em termos de etapas de resolução \\
\hline \multirow{4}{*}{ Representação } & $\begin{array}{l}\text { Utilização dos } \\
\text { conhecimentos linguísticos }\end{array}$ & $\begin{array}{l}\text { Identificar se o enunciado apresenta termos que possam } \\
\text { ser entendidos na língua materna do aluno. }\end{array}$ \\
\hline & \begin{tabular}{|l|} 
Utilização dos \\
conhecimentos semânticos
\end{tabular} & $\begin{array}{l}\text { Evidenciar se o enunciado apresenta termos matemáticos } \\
\text { que são conhecidos pelo aluno. }\end{array}$ \\
\hline & $\begin{array}{l}\text { Utilização dos } \\
\text { conhecimentos } \\
\text { esquemáticos }\end{array}$ & $\begin{array}{l}\text { Perceber se o aluno identificou do que se trata o problema, } \\
\text { por exemplo, se é um problema de geometria, de área, etc. }\end{array}$ \\
\hline & $\begin{array}{l}\text { Perceber se faltam ou } \\
\text { sobram informações }\end{array}$ & $\begin{array}{l}\text { Reconhecer se aluno identificou o que era informação útil } \\
\text { e informação supérflua ao problema. }\end{array}$ \\
\hline \multirow{5}{*}{ Planejamento } & $\begin{array}{l}\text { Utilização do conhecimento } \\
\text { estratégico }\end{array}$ & $\begin{array}{l}\text { Perceber se o aluno utilizou a estratégia adequada ao } \\
\text { problema. }\end{array}$ \\
\hline & $\begin{array}{l}\text { Tipo de mente matemática } \\
\text { (lógico-verbal, viso-pictórico } \\
\text { ou ambos) }\end{array}$ & $\begin{array}{l}\text { Identificar como se sucedeu esta estratégia, ou seja, se ela } \\
\text { é no formato de representações do tipo desenho (viso- } \\
\text { pictórico), por meio de representações algébricas (lógico- } \\
\text { verbal) ou ambas. }\end{array}$ \\
\hline & $\begin{array}{l}\text { Pensar com símbolos } \\
\text { matemáticos }\end{array}$ & $\begin{array}{l}\text { Captar se o aluno está utilizando os símbolos matemáticos } \\
\text { de forma adequada. }\end{array}$ \\
\hline & Generalizar de forma rápida & $\begin{array}{l}\text { Identificar se o aluno generaliza uma dada situação de } \\
\text { matemática. }\end{array}$ \\
\hline & $\begin{array}{l}\text { Abreviar o processo de } \\
\text { raciocínio matemático }\end{array}$ & $\begin{array}{l}\text { Verificar se o aluno utiliza procedimentos que abreviam o } \\
\text { raciocínio sobre o problema. }\end{array}$ \\
\hline \multirow{4}{*}{ Execução } & $\begin{array}{l}\text { Executar a estratégia } \\
\text { proposta }\end{array}$ & $\begin{array}{l}\text { Constatar se o aluno realizou os cálculos de acordo com a } \\
\text { estratégia que havia sido proposta. }\end{array}$ \\
\hline & $\begin{array}{l}\text { Fazer os cálculos } \\
\text { matemáticos necessários }\end{array}$ & $\begin{array}{l}\text { Identificar se todos os cálculos matemáticos que eram } \\
\text { necessários à resolução, foram desenvolvidos de forma } \\
\text { adequada. }\end{array}$ \\
\hline & $\begin{array}{l}\text { Utilização do conhecimento } \\
\text { procedimental }\end{array}$ & $\begin{array}{l}\text { Perceber se os procedimentos de cálculos estão } \\
\text { adequados. }\end{array}$ \\
\hline & $\begin{array}{l}\text { Estabelecimento de relações } \\
\text { quantitativas e espaciais }\end{array}$ & $\begin{array}{l}\text { Evidenciar se relações quantitativas e espaciais foram } \\
\text { estabelecidas. }\end{array}$ \\
\hline \multirow{4}{*}{ Monitoramento } & $\begin{array}{l}\text { Verificação da resposta } \\
\text { apresentada }\end{array}$ & Verificar se a resposta está de acordo com o problema. \\
\hline & $\begin{array}{l}\text { Habilidade para apresentar } \\
\text { racionalidade de uma } \\
\text { solução }\end{array}$ & $\begin{array}{l}\text { Identificar se o aluno apresenta racionalidade de sua } \\
\text { resolução. }\end{array}$ \\
\hline & Rever a resolução seguida & $\begin{array}{l}\text { Perceber se a resolução foi revista pelo aluno após } \\
\text { identificação de algum erro ou correção do professor. }\end{array}$ \\
\hline & $\begin{array}{l}\text { Habilidade de reconstrução } \\
\text { rápida e livre do raciocínio } \\
\text { matemático }\end{array}$ & Identificar foi refeito o que foi proposto de forma adequada. \\
\hline
\end{tabular}

Fonte: Elaborado pelos autores.

Nesta mesma faixa de ensino, Stefani e Proença (2019) analisaram as dificuldades de alunos do $7^{\circ}$ e $8^{\circ}$ anos sobre o conteúdo de perímetro e área. Os autores identificaram que as principais dificuldades estavam relacionadas nos problemas que haviam informações faltantes ou supérfluas. 
O estudo de Matsuda (2017) analisou as dificuldades de 30 alunos do $7^{\circ}$ ano sobre o conteúdo de equações do $1^{\circ}$ grau. A autora destaca que as dificuldades estiveram concentradas na etapa de representação, quando os alunos apresentaram dificuldades sobre "a natureza do problema, termos matemáticos como triplo e múltiplo e ainda as falas das hipóteses" Matsuda (2017, p. 6). Com ênfase, a autora destaca que a má interpretação do problema desencadeou uma sequência de erros.

Esta questão da má interpretação dos problemas é uma temática central nas perspectivas que abordam o problema como ponto de partida. Mendes, Pereira e Proença (2020) pesquisaram sobre as fragilidades nesta perspectiva aplicada ao ensino na formação inicial de professores de Matemática, identificaram que além da dificuldade em relação ao entendimento dos problemas pelos licenciandos, também havia a dificuldade em relação à falta de conhecimentos matemáticos. Desta forma, compreendemos que a partir de uma pertinente avaliação do processo de resolução dos estudantes, é possível desenvolver um processo de ensino com mais qualidade.

\section{Procedimentos Metodológicos}

Este estudo caracteriza-se como descritivo, pois tem como primordialidade a "[...] descrição das características de determinada população ou fenômeno ou o estabelecimento de relações entre variáveis" Gil (2008, p. 28). Sua natureza é qualitativa, pois segundo Chizzotti:

[...] parte do fundamento de que há uma relação dinâmica entre o mundo real e o sujeito, uma interdependência viva entre o sujeito e o objeto, um vínculo indissociável entre o mundo objetivo e a subjetividade do sujeito. $\mathrm{O}$ conhecimento não se reduz a um rol de dados isolados, conectados por uma teoria explicativa; o sujeito observador é parte integrante do processo de conhecimento e interpreta os fenômenos, atribuindo-lhes um significado. O objeto não é um dado inerente e neutro; está possuído de significados e relações que sujeitos concretos criam em suas ações (CHIZZOTTI, 1991, p. 79).

Seguindo esta perspectiva, o presente estudo foi desenvolvido em uma universidade pública do norte do Paraná com 18 acadêmicos do curso de Licenciatura em Matemática. Estes, cursaram a disciplina de Estágio Curricular Supervisionado I que buscou trabalhar o processo de ensino-aprendizagem nos anos finais do Ensino Fundamental. Os dados utilizados nesta pesquisa referem-se a parte de um curso de formação que foi ofertado na disciplina. Desta forma, os estudantes já haviam estudado o que é um problema e sua diferenciação de exercício, as etapas de Resolução de Problemas de Proença (2018) e estratégias de resolução, sendo o primeiro contato deles com o EAMvRP.

Para tanto, buscamos desenvolver a proposta de Proença (2018) do EAMvRP para trabalhar a introdução do conteúdo de operações com frações (adição, subtração, multiplicação e divisão), o qual é abordado no $6^{\circ}$ ano do Ensino Fundamental. A prática foi desenvolvida em duas aulas na perspectiva do ensino remoto, com duração de $1 \mathrm{~h} 40 \mathrm{~min}$ cada aula. No caso, os $1^{\circ}$ e $2^{\circ}$ 
autores eram, respectivamente, o professor doutorando que estava desenvolvendo sua pesquisa de tese e o professor regente da turma. Cabe ressaltar que a pesquisa foi realizada no segundo semestre de 2020, quando o Brasil enfrentava a pandemia da Covid-19 e, desta forma, as medidas de distanciamento estavam vigentes.

Para tanto, as plataformas do Google Meet e do Discord foram utilizadas para a realização das aulas. No caso, o Google Meet ajudou nas discussões entre os participantes e professores. Já o uso do Discord propiciou o trabalho em grupos. As aulas foram gravadas e transcritas para que os dados pudessem ser analisados a luz das etapas de Resolução de Problemas de Proença (2018). Outrossim, destacamos que para esta análise foram usadas as conversas que foram gravadas e as estratégias de resolução feitas pelos grupos. Para manter o sigilo dos participantes da pesquisa, seguimos as seguintes denominações:

- P1: Professor doutorando que estava fazendo a pesquisa;

- P2: Professor regente na disciplina de Estágio Curricular Supervisionado I;

- $L+n^{0}$ : Licenciando número $n$ participante da formação.

- $G+n^{\circ}$ (antes de uma denominação): Significa que a conversa está ocorrendo no Discord no grupo n (Por exemplo G1_L2, no grupo 2 o licenciando 2 está falando).

Para desenvolver o trabalho de EAMvRP, utilizamos as quatro situações matemáticas referentes ao conteúdo de operação com frações, apresentadas no estudo de Proença (2019b), a saber: adição, subtração, multiplicação e divisão. No entanto, como o conteúdo em si era relativamente fácil aos licenciandos, optamos por reelaborar as situações, adicionando informações supérfluas para favorecer a discussão e reflexão entre os grupos em termos de etapas de resolução. A Tabela 2 apresenta as situações originais e reelaboradas.

Tabela 2 - Situações Matemáticas reelaboradas de Proença (2018)

\begin{tabular}{|c|c|c|}
\hline & Proença (2019b) & Situação de Matemática reelaboradas \\
\hline 1 - Adição & $\begin{array}{l}\text { Sílvio e Lúcio estão participando } \\
\text { de uma corrida de bicicleta. } \\
\text { Sílvio já percorreu } 3 / 4 \text { do trajeto e } \\
\text { Lúcio percorreu } 1 / 2 \text { do trajeto. } \\
\text { Qual o total percorrido pelos } \\
\text { dois juntos? (PROENÇA, } 2019 b \text {, } \\
\text { p. 9). }\end{array}$ & $\begin{array}{l}\text { As bicicletas têm diversas cores, podendo ser azul, } \\
\text { vermelha, preta, branca, entre outras. No Brasil, a } \\
\text { bicicleta de cor vermelha é a mais vendida para os } \\
\text { participantes de corrida com bicicletas. Silvio e Lúcio } \\
\text { estão participando de uma corrida de bicicleta. Silvio } \\
\text { já percorreu } 3 / 4 \text { do trajeto e Lúcio percorreu } 1 / 2 \text { do } \\
\text { trajeto. Neste dia da corrida, está fazendo calor e os } \\
\text { termômetros marcam } 32^{\circ} \text {. Qual o total percorrido } \\
\text { pelos dois juntos? }\end{array}$ \\
\hline 2 - Subtração & $\begin{array}{l}\text { Sílvio e Lúcio estão participando } \\
\text { de uma corrida de bicicleta. } \\
\text { Sílvio já percorreu } 3 / 4 \text { do trajeto e } \\
\text { Lúcio percorreu } 1 / 2 \text { do trajeto. } \\
\text { Qual a diferença entre o que } \\
\text { cada um percorreu? } \\
\text { (PROENÇA, 2019b, p. 11). }\end{array}$ & $\begin{array}{l}\text { As bicicletas têm diversas cores, podendo ser azul, } \\
\text { vermelha, preta, branca, entre outras. No Brasil, a } \\
\text { bicicleta de cor vermelha é a mais vendida para os } \\
\text { participantes de corrida com bicicletas. Silvio e Lúcio } \\
\text { estão participando de uma corrida de bicicleta. Silvio } \\
\text { já percorreu } 3 / 4 \text { do trajeto e Lúcio percorreu } 1 / 2 \text { do } \\
\text { trajeto. Neste dia da corrida, está fazendo calor e os } \\
\text { termômetros marcam } 32^{\circ} \text {. Qual a diferença entre o } \\
\text { que cada um percorreu? }\end{array}$ \\
\hline
\end{tabular}




\begin{tabular}{|c|c|c|}
\hline 3 - Multiplicação & $\begin{array}{l}\text { Sílvio e Lúcio estão participando } \\
\text { de uma corrida de bicicleta. } \\
\text { Sílvio já percorreu } 3 / 4 \text { do trajeto e } \\
\text { Lúcio, } 1 / 2 \text { do que Sílvio } \\
\text { percorreu. Qual parte do trajeto } \\
\text { Lúcio percorreu? (PROENÇA, } \\
\text { 2019b, p. 12). }\end{array}$ & $\begin{array}{l}\text { As bicicletas têm diversas cores, podendo ser azul, } \\
\text { vermelha, preta, branca, entre outras. No Brasil, a } \\
\text { bicicleta de cor vermelha é a mais vendida para os } \\
\text { participantes de corrida com bicicletas. Silvio e Lúcio } \\
\text { estão participando de uma corrida de bicicleta. Silvio } \\
\text { já percorreu } 3 / 4 \text { do trajeto e Lúcio, } 1 / 2 \text { do que Silvio } \\
\text { percorreu. Neste dia da corrida, está fazendo calor e } \\
\text { os termômetros marcam } 32^{\circ} \text {. Qual parte do trajeto } \\
\text { Lúcio percorreu? }\end{array}$ \\
\hline 4 - Divisão & $\begin{array}{l}\text { Sílvio e Lúcio estavam } \\
\text { estudando Matemática na casa } \\
\text { de suas amigas, Ana e Paula, } \\
\text { na sexta-feira à noite. Como } \\
\text { estavam com fome, decidiram } \\
\text { ligar em uma pizzaria e pediram } \\
\text { uma pizza grande do tipo } \\
\text { portuguesa. Quando a pizza } \\
\text { chegou, decidiram comer } \\
\text { apenas metade da pizza. Tendo } \\
\text { em vista essa decisão, que } \\
\text { parte da pizza comeu cada um } \\
\text { dos quatro amigos? } \\
\text { (PROENÇA, 2019b, p. 14). }\end{array}$ & $\begin{array}{l}\text { O ato de estudar pode gerar fome nos alunos. } \\
\text { Sabendo disso, Sílvio e Lúcio estavam estudando } \\
\text { Matemática na casa de suas amigas, Ana e Paula, } \\
\text { na sexta-feira à noite. Como estavam com fome, } \\
\text { decidiram ligar em uma pizzaria e pediram uma } \\
\text { pizza grande do tipo portuguesa. Na pizzaria havia } \\
\text { os sabores de frango com catupiry, quatro queijos e } \\
\text { rúcula com bacon. Quando a pizza chegou, } \\
\text { decidiram comer apenas metade da pizza. Tendo em } \\
\text { vista essa decisão, que parte da pizza comeu cada } \\
\text { um dos quatro amigos? }\end{array}$ \\
\hline
\end{tabular}

Fonte: Elaborado pelos autores.

O processo de resolução ocorreu em grupos. Na Tabela 3, apresentamos os grupos de licenciandos que foram formados, bem como as situações matemáticas que eles ficaram responsáveis por resolver. Outrossim, apresentamos também quais situações foram selecionadas para a nossa análise dentre as resolvidas pelos grupos, de forma em que demos preferência para uma por cada operação matemática.

Tabela 3 - Divisão das situações matemáticas nos respectivos grupos

\begin{tabular}{|c|c|c|c|}
\hline Grupo & Licenciandos & Situação de Matemática & Análise \\
\hline G1 & L7 e L8 & 01 (adição) e 03 (multiplicação) & 03 (multiplicação) \\
\hline G2 & L1, L10 e L12 & 01 (adição) e 04 (divisão) & 01 (adição) \\
\hline G3 & L2, L6 e L13 & 02 (subtração) e 03 (multiplicação) & 04 (divisão) \\
\hline G4 & L4 e L5 & 02 (subtração) e 04 (divisão) & Não selecionado \\
\hline G5 & L3, L9 e L11 & 03 (multiplicação) e 04 (divisão) & 02 (subtração) \\
\hline
\end{tabular}

Fonte: Elaborado pelos autores.

Conforme se observa na Tabela 3, quatro resoluções foram selecionadas referentes ao G1 (multiplicação), G2 (adição), G3 (divisão) e G5 (subtração). A resolução do G4 não foi selecionada, pois o grupo chegou a fazer a resolução durante a primeira aula, mas na segunda apresentou somente os conhecimentos matemáticos. A análise dos dados foi organizada em termos da terceira e da quarta ação do EAMvRP: auxílio aos alunos durante a resolução e discussão das estratégias dos alunos ao conteúdo. Assim, para a terceira ação, apresentamos em quadros as etapas de Resolução de Problemas de Proença (2018) e falas advindas da formação referente 
que compõem a descrição feita pelo autor em cada etapa, conforme apresentamos na Tabela 1 (o que consideramos como categorias). Por conseguinte, na quarta ação, apresentamos uma resolução referente a cada uma das quatro situações de matemática e como os licenciandos explicaram sua resolução.

\section{Resultados e Discussão: O Processo de Resolução de Problemas na $3^{a}$ Ação}

A terceira ação do EAMvRP ocorreu no Discord ( $1^{\mathrm{a}}$ aula) com os licenciandos separados em grupos, conforme a Tabela 3. Observações puderam ser feitas sobre as etapas de representação, planejamento e execução. Na Tabela 4, apresentamos as descrições da etapa de representação e as falas que a compõem.

Tabela 4 - Avaliação da etapa de representação

\begin{tabular}{|c|c|}
\hline Representação & Falas dos participantes \\
\hline $\begin{array}{l}\text { Utilização dos } \\
\text { conhecimentos } \\
\text { semânticos }\end{array}$ & $\begin{array}{l}\text { G2_L1: [...] a pergunta falou que eles comeram só metade. Quando a pizza chegou } \\
\text { decidiram comer apenas metade da pizza. Aí eles querem saber que parte da pizza } \\
\text { comeu os amigos. Cada um. } \\
\text { G2_L12: O problema é que a gente não sabe se eles comerão partes iguais ou } \\
\text { não. Você sabe que eles comeram metade. }\end{array}$ \\
\hline \multirow[b]{2}{*}{$\begin{array}{l}\text { Utilização dos } \\
\text { conhecimentos } \\
\text { esquemáticos }\end{array}$} & $\begin{array}{l}\text { G4_L5: Então, o objetivo é calcular a diferença entre o percurso de cada atleta, } \\
\text { certo? }\end{array}$ \\
\hline & $\begin{array}{l}\text { G5_L3: Aqui como é fração e é número picado, geralmente nestas situações a } \\
\text { gente aplica aos alunos com as ideias de dividir comida, né? Pizza é uma delas e } \\
\text { como é uma corrida, eu tenho o circuito então podia ser oval que é circular e dá } \\
\text { para ser similar com pizza, mas foi ideia minha isso ai, se der furada nós descarta. }\end{array}$ \\
\hline \multirow{3}{*}{$\begin{array}{l}\text { Perceber se faltam ou } \\
\text { sobram informações }\end{array}$} & $\begin{array}{l}\text { G2_P1: Qual parte ali que vocês ficaram em dúvida? } \\
\text { G2_L10: Ah, porque assim, ele apresentou a temperatura do dia, apresentou uma } \\
\text { informação sobre as cores da bicicleta, só que ele não usou essas informações, ele } \\
\text { só perguntou o trajeto só porque é uma situação matemática? Por isso que ele } \\
\text { apresentou outras informações ou? } \\
\text { G2_P1: Vocês lembram quando a gente trabalhou as etapas de resolução e, na } \\
\text { primeira, devemos verificar a situação e identificar se há informações supérfluas ou } \\
\text { faltantes? } \\
\text { G2_L10: A sim, agora entendi. Lembrei sim. }\end{array}$ \\
\hline & $\begin{array}{l}\text { G4_L4: Nessa da representação é a compreensão é a interpretação e além disso é } \\
\text { compreender a estrutura formal do problema. Aí tipo, aqui tem essas informações } \\
\text { que são mais o que tá me confundindo. Que eu tô achando meio desnecessário } \\
\text { assim. }\end{array}$ \\
\hline & $\begin{array}{l}\text { G3_L2: Esse problema não tem a ver com a questão da temperatura e as cores } \\
\text { tempo? } \\
\text { G3_P1: Isso, então aí que tá. } \\
\text { G3_L2: Porque ele pede pra trajetória, né? } \\
\text { G3_P1: Sim, isso aí. Vocês acham que interferiria ali? } \\
\text { G3_L2: Eu acho que não. } \\
\text { G3_P2: E as colegas de vocês? } \\
\text { G3_L6: Eu também acho que não, acho que isso aí só confundira mais o aluno. }\end{array}$ \\
\hline
\end{tabular}
Fonte: Dados da pesquisa (2021).

A respeito da etapa de representação, sobre a utilização dos conhecimentos semânticos, evidenciamos que os estudantes do G2 tiveram dúvidas na interpretação da terminologia "metade 
da pizza", uma vez que o problema não falava se era em partes iguais ou não. A utilização dos conhecimentos semânticos de forma adequada é bastante importante nesse início de resolução, pois conforme mostrou o trabalho de Matsuda (2017), pode desencadear uma sequência de erros.

Quanto à categoria referente à utilização do conhecimento esquemático, observamos que estes ocorreram de forma adequada pelos grupos $\mathrm{G} 4$ e G5, visto que compreenderam qual era o esquema do problema, ou seja, o que precisam para resolvê-lo. Para Proença $(2018$, p. 25) ao se "[...] identificar o esquema adequado, a pessoa tem condições de guiar a atenção e discernir entre dados relevantes e irrelevantes".

Por fim, sobre a categoria de perceber se há informações úteis ou supérfluas, observa-se que inicialmente os acadêmicos do G2, G3 e G4 não abordaram o problema na perspectiva de etapas de resolução, ou seja, a etapa de representação de forma adequada e desta forma, enquanto o professor não os avisou, estes grupos não realizaram adequadamente o ato de identificar que estavam sobrando informações. Isso também foi identificado no trabalho de Stefani e Proença (2019), o que mostra que a dificuldade de entender as informações que são úteis ao problema, também pode ocorrer no Ensino Superior. No entanto, com as mediações do professor os grupos procederam de acordo. A Tabela 5 a seguir mostra as descrições da etapa de planejamento e as falas que a compõem.

Tabela 5 - Avaliação da etapa de planejamento

\begin{tabular}{|c|c|}
\hline Planejamento & Falas dos participantes \\
\hline $\begin{array}{l}\text { Tipo de mente matemática } \\
\text { (lógio-verbal, viso-pictórico } \\
\text { ou ambos) }\end{array}$ & $\begin{array}{l}\text { G1_L8: A gente tá pensando em como representa em desenho, vamos } \\
\text { pensar assim, a metade de três quartos, como se fosse uma criança de } \\
\text { ensino fundamental um. }\end{array}$ \\
\hline \multirow[t]{2}{*}{$\begin{array}{l}\text { Pensar com símbolos } \\
\text { matemáticos }\end{array}$} & $\begin{array}{l}\text { G4_L5: Depois, mostrando aqui que é três quartos, pro aluno, metade que é } \\
\text { um meio, divide em duas parte que é um quarto.... } \\
\text { G4_L4: Se a gente partir do ponto que eles já têm um conhecimento prévio } \\
\text { sobre fração e se a gente vai introduzir, vai começar a introduzir operação } \\
\text { com a fração, né? Seria isso na cabeça do aluno, pois se você vai introduzir, } \\
\text { ele não saberia MMC. }\end{array}$ \\
\hline & $\begin{array}{l}\text { G1_L7: O que você falou é de colocar as representações, duas linhas iguais } \\
\text { e colocar metade, um meio e também fazer a mesma representação só que } \\
\text { dividindo em quatro, é isso? Ele pegaria dois partes dela, daria a mesma } \\
\text { coisa. }\end{array}$ \\
\hline Generalizar de forma rápida & $\begin{array}{l}\text { G1_L7: Aí a gente vai tá mostrando essa associação entre o } \frac{1}{2} \text { e } \circ \frac{2}{4} \text { que são } \\
\text { iguais, né? }\end{array}$ \\
\hline
\end{tabular}

Fonte: Dados da pesquisa (2021).

Nesta etapa, os alunos deveriam elaborar um plano para a resolução do problema. O G1 apresentou um tipo de mente viso-pictórico, uma vez que partiram para a elaboração de uma resolução por meio de um desenho. Cabe ressaltar que todos os grupos apresentaram esse tipo de mente, visto que posteriormente, na próxima ação, todos apresentaram estratégias utilizando 
desenhos. Para Krutettskii (1976) isso implica nas estratégias que os alunos podem optar por desenvolver.

Outro ponto observado foi em relação ao conteúdo ser conhecido pelos acadêmicos, o que implicou na utilização da simbologia matemática de frações por todos os grupos, visto que apesar de utilizarem o desenho, consideraram a necessidade de o representá-lo como fração para justificá-lo. Krutettskii (1976) explica que isso ocorre devido a habilidades referentes ao processamento da informação.

Por fim, especificamente para os grupos que pegaram o problema de soma de frações, foi perceptível a necessidade de uma generalização rápida em relação a utilização de frações equivalentes para representar $\frac{1}{2}$ como $\frac{2}{4}$, como destaca o G1. Isso permitiu a não utilização dos cálculos com o Mínimo Múltiplo Comum, agilizando sua resolução. Na Tabela 6 apresentamos as descrições da etapa de execução e as falas que a compõem.

Tabela 6 - Avaliação da etapa de execução

\begin{tabular}{|c|l|}
\hline Execução & \multicolumn{1}{c|}{ Falas dos participantes } \\
\hline $\begin{array}{c}\text { Fazer os cálculos } \\
\text { matemáticos } \\
\text { necessários }\end{array}$ & $\begin{array}{l}\text { G5_L9: Então, qual que é a diferença entre os dois? Ah, seria só diminuir as } \\
\text { expressões, que é três quartos, menos um meio, né? }\end{array}$ \\
\hline \multirow{4}{*}{$\begin{array}{c}\text { Desenhar elementos } \\
\text { viso-pictóricos }\end{array}$} & $\begin{array}{l}\text { G1_P1: Olá, e aí como vocês estão fazendo? } \\
\text { G1_A8: A gente tá pensando em como representa com desenho, vamos desenhar } \\
\text { assim, a metade de três quartos, como se uma criança de ensino fundamental um. }\end{array}$ \\
\cline { 2 - 2 } & $\begin{array}{l}\text { G5_P1: Olá grupo, como vocês fizeram? } \\
\text { G5_A11: Então, L9 até ilustrou ali, ó, do jeito que ele que ele faria, né? E mais, a } \\
\text { gente fez tudo de uma maneira de círculo então nosso objetivo ali foi trazer pra mais } \\
\text { pro visual. }\end{array}$ \\
\cline { 2 - 3 } & $\begin{array}{l}\text { G1_L8: No começo da introdução da fração, como na barra de chocolate, a gente } \\
\text { pode tipo dar uma dica de assim, fazer o desenho das pistas. }\end{array}$ \\
\hline \multirow{2}{*}{$\begin{array}{c}\text { Utilização do } \\
\text { conhecimento } \\
\text { procedimental }\end{array}$} & $\begin{array}{l}\text { G1_L7: Fazer igual você falou, separar ela em quatro partes e separar em 4 } 4 \\
\text { percursos em um retângulo inteiro, né? E por exemplo, você desenha uma outra } \\
\text { com o mesmo tamanho, divididinho em duas, na mesma marca onde tá o a outra } \\
\text { divisão? Fala quem ta em uma parte e outro ta em outra. }\end{array}$ \\
\hline
\end{tabular}
Fonte: Dados da pesquisa (2021).

Como os problemas trabalhados eram sobre operações de frações, observa-se na primeira categoria que para os licenciandos, fazer os cálculos matemáticos não se tornou um impeditivo. Compreendemos que a resolução por meio dos cálculos foi a parte mais fácil. Por outro lado, o processo de ter que resolver os problemas, levando-se em consideração como se fosse alunos que estariam aprendendo as operações, tornou a atividade mais interessante aos grupos. Desta forma, observamos na segunda categoria que todos os grupos optaram por desenhar elementos viso-pictóricos.

Por fim, evidenciamos o G1 colocando em prática o plano que haviam traçado e utilizando o conhecimento procedimental para resolver o problema. De acordo com Mayer (1985), realizar 
operações de divisão e multiplicação tem grande importância na Resolução de Problemas. Cabe ressaltar que nesta aula da terceira ação não foi possível observar as descrições pertinentes à etapa de monitoramento, uma vez que os grupos ficaram para terminar suas resoluções em casa.

\section{Resultados e Discussão: O Processo de Resolução de Problemas na $4^{a}$ Ação}

Neste momento, os acadêmicos se reuniram no Google Meet ( $2^{\mathrm{a}}$ aula) para apresentarem suas resoluções. Apesar de haver mais de uma resolução para um mesmo problema, selecionamos quatro resoluções referentes a cada uma das operações aritméticas com frações. Referente ao primeiro problema, a Figura 1 mostra a resolução feita pelo grupo 2.

Figura 1 - Resolução do problema 1 de adição feito pelo grupo 2

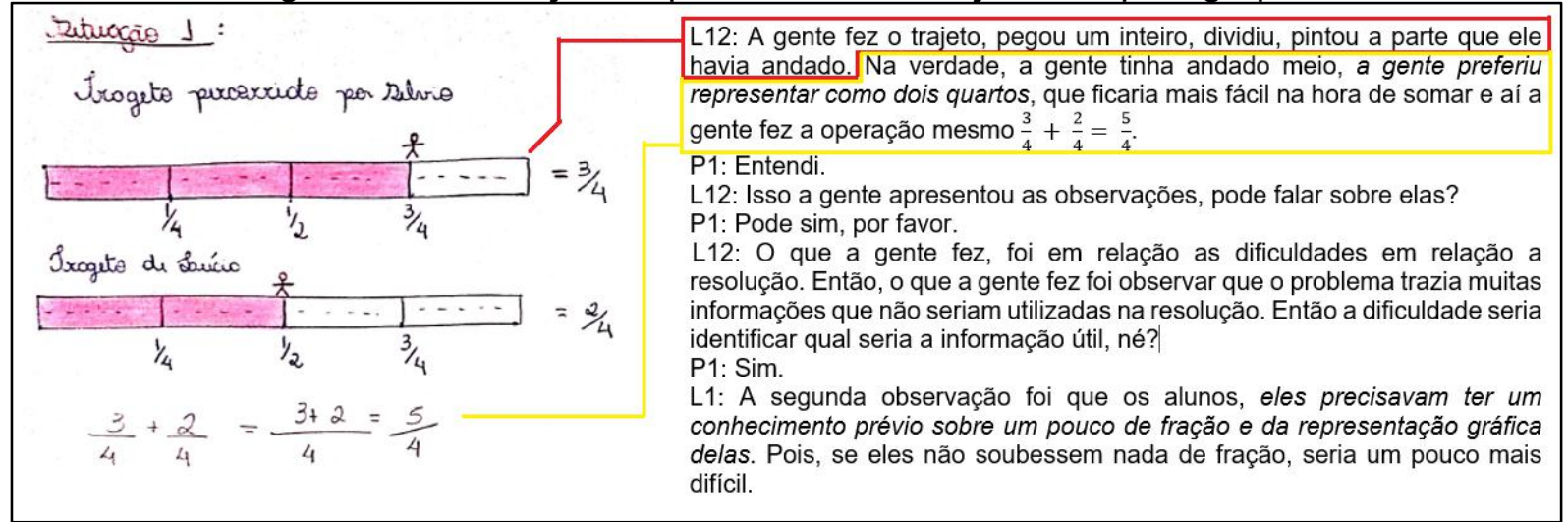

Fonte: Dados da pesquisa (2021).

Com base na Figura 1, percebe-se que o G2 transcreveu no formato de um desenho a sua representação mental sobre a representação gráfica, evidenciando a etapa de representação. Os conhecimentos linguísticos e semânticos não foram obstáculos ao grupo. Quanto ao conhecimento esquemático, identifica-se na marcação em amarelo na Figura 1 que o grupo compreendeu do que se tratava o problema e buscou um caminho, de modo a facilitar a interpretação do mesmo até para alunos que estivessem aprendendo este conteúdo, objetivo este o EAMvRP.

Quanto à etapa de planejamento, o conhecimento estratégico abordado pelo grupo foi o do desenvolvimento de um desenho apontando para um tipo de mente viso-pictórica. No entanto, o grupo também pensou com símbolos matemáticos, visto que os representou posteriormente para justificar a representação gráfica. Percebemos que ao transformar $\frac{1}{2}$ em $\frac{2}{4}$ o grupo abreviou o processo de raciocínio lógico, transformando por meio de frações equivalentes e assim, facilitando a soma das frações sem o uso do MMC. Desta forma, abreviar o processo de resolução é um indício de habilidade matemática (KRUTETSKII, 1976). 
$\mathrm{Na}$ etapa de execução, observamos na Figura 1 que para a estratégia proposta pelo grupo os cálculos matemáticos foram feitos corretamente, bem como os desenhos. Desta forma, o uso do conceito de frações equivalentes favoreceu o uso adequado dos conhecimentos procedimentais.

Por fim, na etapa de monitoramento não há uma resposta apresentada para o problema, mas sim, somente os cálculos com um valor que indica a resposta. Outrossim, nota-se na fala de L12 uma certa verificação do final do problema e sua adequação ao que foi solicitado, uma vez que o grupo evidenciou críticas construtivas.

O segundo problema abordado foi referente a subtração de frações, conforme verifica-se na Figura 2.

Figura 2 - Resolução do problema 2 de subtração feito pelo grupo 5

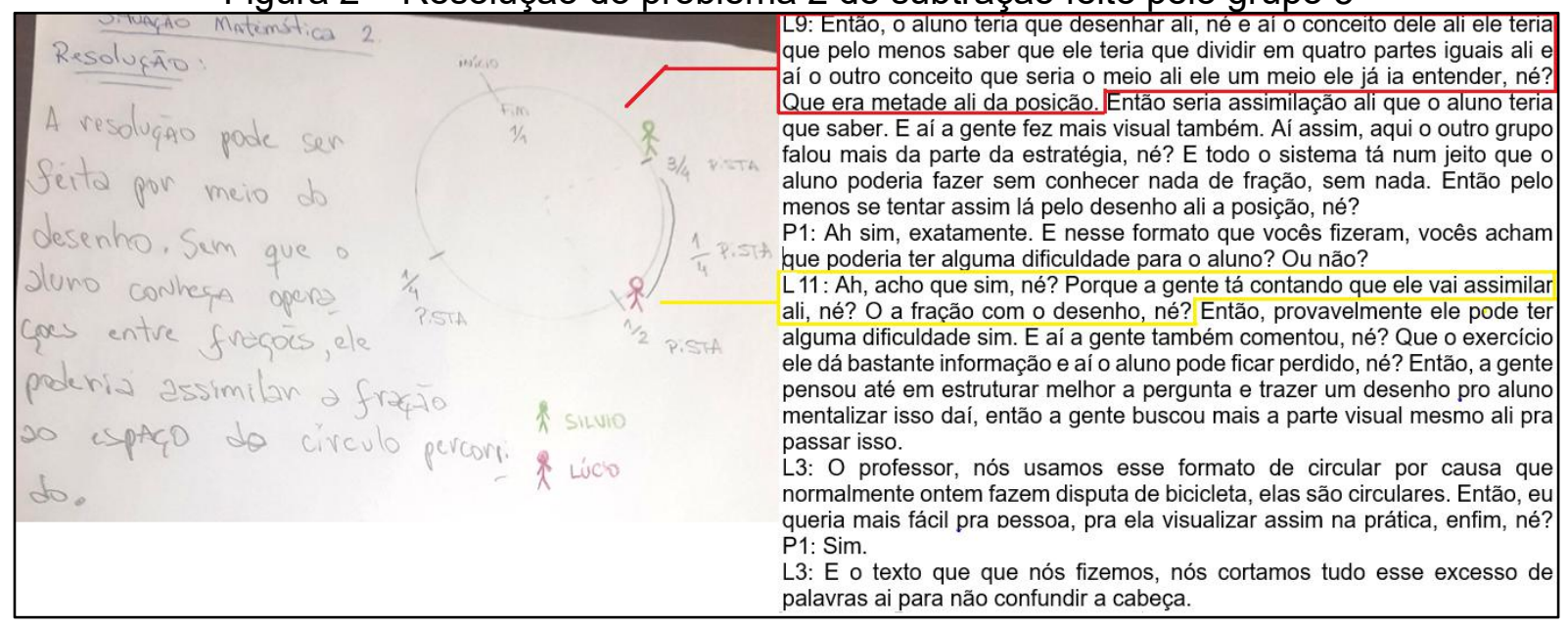

Fonte: Dados da pesquisa (2021).

Com base na Figura 2, observamos que na etapa de representação, pensar no contexto da situação de matemática, ou seja, em uma pista circular de corrida de bicicleta, favoreceu uma representação mental mais adequada. O G5 não apresentou dificuldades em relação aos conhecimentos linguísticos e semânticos. Para o G5, além da utilização dos conhecimentos prévios, contextualizar a situação de matemática também favoreceu a utilização do conhecimento esquemático. Neste grupo, também se identificou interessantes reflexões sobre a análise das informações supérfluas ou faltantes. A respeito desses três conhecimentos, Proença (2018, p. 27) destaca que "[...] uma pessoa que consegue realizar essa etapa de representação do problema de forma adequada apresenta habilidade matemática para a compreensão da estrutura formal do problema". Ou seja, ela tem condições de perceber se faltam ou sobram informações.

$\mathrm{Na}$ etapa de planejamento, o G5 também apresentou um tipo de mente viso-pictórico e, por utilizarem um desenho de forma contextualizada sobre a situação de matemática, a utilização dos símbolos matemáticos ficou em um segundo plano. Na etapa de execução, o grupo executou a 
estratégia conforme haviam pensando, ou seja, responderam fazendo um desenho circular. Desta forma, foi possível observar de forma mais clara as relações quantitativas e espaciais, conforme Proença (2018) chamou a atenção nesta etapa.

Na etapa de monitoramento, o G5 também não apresentou a resposta final. No entanto, ao destacarem a intenção de refazer o problema proposto, deixando-o mais "limpo", sugere que reviram a solução no sentido de compreendê-la e deixar somente o que era necessário.

O terceiro problema abordado foi referente a multiplicação de frações, conforme verifica-se na Figura 3.

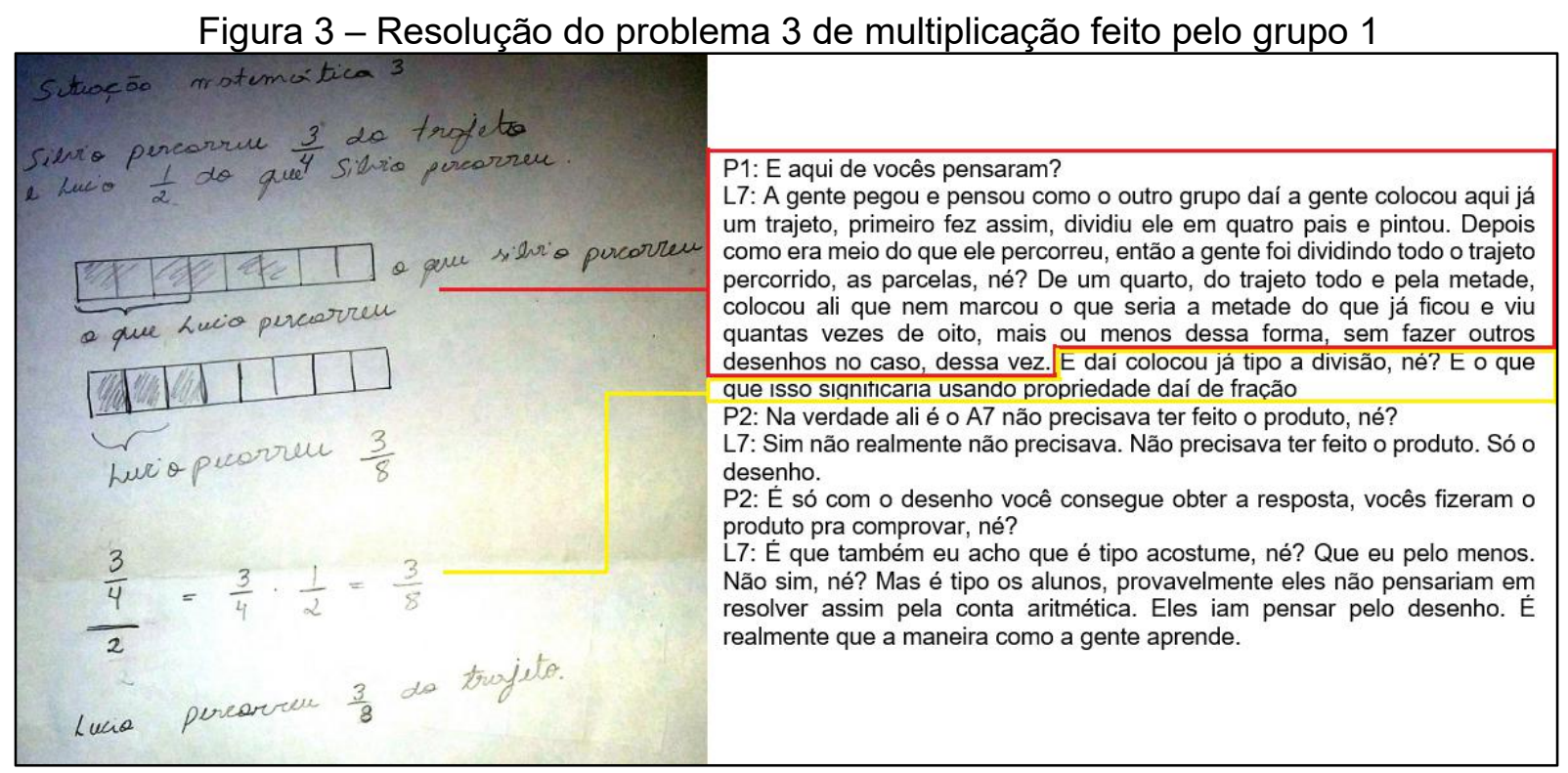

Fonte: Dados da pesquisa (2021).

Referente à etapa de representação, o G1 explica passo a passo sua representação mental sobre a resolução, bem com o esquema que acessaram para explicar a multiplicação por meio de desenhos. Este grupo não havia inicialmente entendido as informações que estavam presentes no problema, tendo o professor que retomar as etapas. Resultados como este também foram encontrados no trabalho de Luz e Proença (2019).

$\mathrm{Na}$ etapa de planejamento, observa-se também um tipo de mente viso-pictórico, bem como a utilização do símbolo matemático de fração para justificar o desenho dos retângulos, o qual correspondeu a estratégia utilizada. Na etapa de execução, a Figura 3 evidencia que o G1 executou a estratégia por meio de cálculos e do desenho. Outrossim, o G1 busca apresentar o procedimento de multiplicação de frações por meio da divisão de frações. Por fim, este foi um dos poucos grupos que apresentaram uma resposta favorável à etapa de monitoramento. Proença (2018) considera que a avaliação da resposta é um importante aspecto que deve ser cumprido nesta etapa. 
O último problema é relativo ao conteúdo de divisão de frações, o qual é apresentado na Figura 4.

Figura 4 - Resolução do problema 4 de divisão feito pelo grupo 3

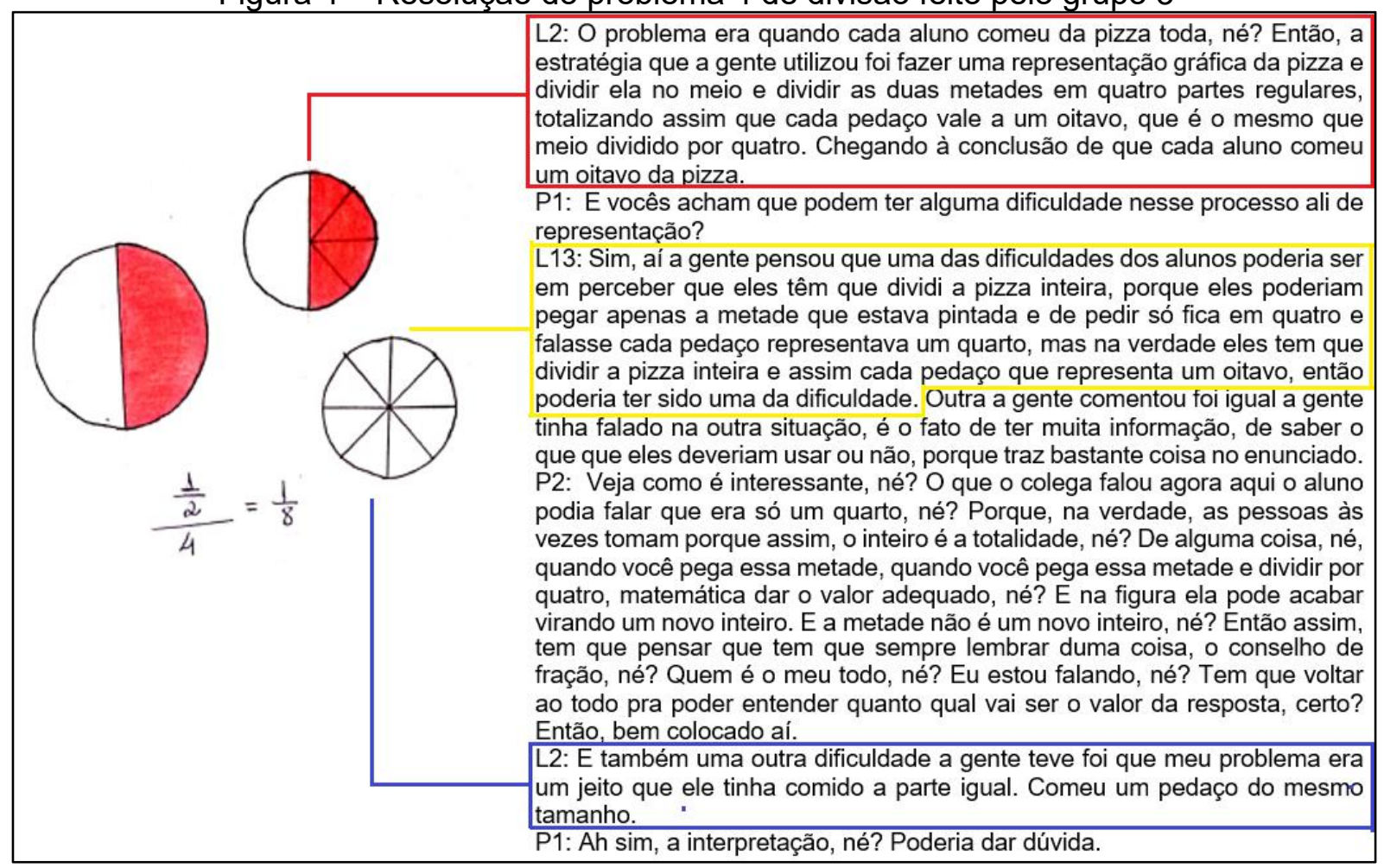

Fonte: Dados da pesquisa (2021).

Com base na Figura 4, evidencia-se na etapa de representação que o G3 desenhou círculos para representar a pizza. No entanto, somente pelo desenho apresentado pelo G3 é difícil interpretar o que o grupo gostaria de fazer. Para tanto, buscamos subsídios em sua explicação teórica. Na etapa de planejamento, ao terem um tipo de mente matemática viso-pictórica, utilizaram para expressar seu entendimento por meio do desenho da divisão da pizza.

Quanto à etapa de execução, o G3 apresentou seu desenho do que haviam pensado, ou seja, puderam utilizar adequadamente o conceito de fração em relação a representação do todo em que há primeiro um desenho representando a divisão da pizza na metade. Posteriormente, há um desenho que representa que uma das metades foi dividida entre os amigos em 4 partes e, por fim, o G3 busca mostrar no terceiro desenho (que não está pintado) que a parte que foi dividida para cada amigo corresponde a $\frac{1}{8}$ o que implica no uso adequado do conhecimento procedimental. No entanto, acreditamos que faltou pintar de vermelho o valor de $\frac{1}{8}$, porque isso favorece perceber as relações quantitativas e espaciais de forma mais adequada.

Por fim, referente à etapa de monitoramento, o G3 também não apresentou uma resposta final para o problema, mas, em sua explicação, ao destacarem a necessidade de se observar 
quem era o todo, sugere-se que o grupo compreendeu se a resposta estaria de acordo com o problema.

\section{Considerações Finais}

O objetivo desta pesquisa consistiu em analisar o processo de Resolução de Problemas de licenciandos em formação inicial no contexto formativo do Ensino-Aprendizagem de Matemática via Resolução de Problemas. Esta análise ocorreu por meio das etapas de Proença (2018), a saber: representação, planejamento, execução e monitoramento em que levamos em consideração as ações de auxílio aos alunos durante a resolução e de discussão das estratégias dos alunos ao conteúdo.

A respeito da etapa de representação, identificamos que todos os grupos utilizaram desenhos para representar suas resoluções, o que indica um tipo de mente viso-pictórica. Percebemos que, de forma geral, os grupos não tiveram grandes dificuldades a respeito dos conhecimentos semânticos, linguísticos e esquemáticos. Isso favoreceu que os grupos identificaram que havia informações supérfluas ao problema, conforme Proença (2018) ressalta a respeito dessa etapa.

Sobre a etapa de planejamento identificamos que apesar da utilização de representações viso-pictóricas, os acadêmicos acabaram também pensando com símbolos matemáticos e os utilizando para justificar os desenhos. A respeito da operação de adição e subtração de frações, notamos que a utilização de frações equivalentes entre $\frac{1}{2}$ para $\frac{2}{4}$ favoreceu a generalização rápida para a resolução do problema, sem a necessidade de desenvolver a operação de Mínimo Múltiplo Comum.

$\mathrm{Na}$ etapa de execução os licenciandos não apresentaram maiores dificuldades, uma vez que deveriam apenas executar os cálculos entre as operações de frações, ou seja, somar, subtrair, dividir e multiplicar frações. Por fim, a etapa de monitoramento consistiu na menos desenvolvida pelos grupos, uma vez que somente um dos grupos se preocupou em dar uma resposta final ao problema, verificando se estava de acordo.

À vista disso, consideramos que o objetivo do artigo foi alcançado de forma que olhar para o EAMvRP e, em específico, olhar com as etapas de Resolução de Problemas de Proença (2018) possibilitou uma análise em profundidade, a compreensão das possíveis dificuldades dos licenciandos e uma formação profícua aos participantes.

Nesse sentido, nosso trabalho vislumbra a colaboração com o desenvolvimento de propostas de ensino na perspectiva do EAMvRP, pois possibilita uma avaliação detalhada do 
processo de Resolução de Problemas. Outrossim, a Tabela 1 pode colaborar neste processo favorecendo que o professor tenha um olhar mais crítico sobre o seu ensino.

Desta forma, acreditamos que para estudos futuros, não somente o Ensino-aprendizagem de Matemática via Resolução de Problemas deva ser desenvolvido, mas também que avaliações detalhadas das dificuldades dos alunos nas $3^{a}$ e $4^{a}$ ações, devam ser desenvolvidas em termos de etapas de Resolução de Problemas.

\section{Referências}

ARAUJO, Natália Keli Santos. Análise das dificuldades na resolução de problemas matemáticos por alunos do $5^{\circ}$ ano do ensino fundamental. Orientadora: Veleida Anahi da Silva. 2015. 139 f. Dissertação (Mestrado em Ensino de Ciências e Matemática) - Universidade Federal de Sergipe, São Cristóvão, 2015. Disponível em: https://ri.ufs.br/jspui/handle/riufs/5174. Acesso em: 27 dez. 2021.

BRASIL. Ministério da Educação. Secretaria de Ensino Fundamental. Parâmetros Curriculares Nacionais: $3^{\circ}$ e $4^{\circ}$ Ciclos. Brasília: SEF/MEC, 1998.

BRITO, M. R. F. Alguns aspectos teóricos e conceituais da solução de problemas matemáticos. In: BRITO, M. R. F. (org.). Solução de Problemas e a Matemática escolar. Campinas: Alínea, 2006.

CHIZZOTTI, A. Pesquisa em Ciências humanas e sociais. São Paulo: Cortez, 1991.

GIL, A. C. Métodos e técnicas de pesquisa social. 6. ed. São Paulo: Atlas, 2008.

KRUTETSKII, V. A. The psychology of mathematical abilities in schoolchidren. Tradução de João Teller, do russo para o inglês. Chicago: University of Chicago Press, 1976.

LUZ, J. A. da; PROENÇA, M. C. Resolução de Problemas de Geometria Espacial: Análise das dificuldades de alunos do ensino médio em questões do ENEM 2018. In: ENCONTRO PARANAENSE DE EDUCAÇÃO MATEMÁTICA, 15., 2019, Londrina. Anais [...]. Londrina: SBEMPR, 2019. p. 1-12. Disponível em:

http://www.sbemparana.com.br/eventos/index.php/EPREM/XV EPREM/paper/viewFile/1016/904. Acesso em: 27 dez. 2021.

MATSUDA, F. F. S. Um ensino de equação do $1^{\circ}$ grau com uma incógnita via resolução de problemas. Orientador: Marcelo Carlos de Proença. 2017. 131 f. Dissertação (Mestrado em Ensino de Ciências e Educação Matemática) - Universidade Estadual de Maringá, 2017. Disponível em: http://repositorio.uem.br:8080/jspui/handle/1/4499. Acesso em: 27 dez. 2021.

MAYER, R. E. Implications of cognitive psychology for instruction in mathematical problem solving. In: SILVER, E. A. (ed.). Teaching and learning mathematical problem solving: multiple research perspectives. Hillsdale: LEA, 1985.

MENDES, L. O. R.; AFONSO, E. J. M.; PROENÇA, M. C. Análise da compreensão de licenciandos em Matemática sobre o ensino via Resolução de Problemas. Educação Matemática Debate, Montes Claros, v. 4, n. 10, e202011, p. 1-23, 9 abr. 2020. DOI: https://doi.org/10.24116/emd.e202011. 
MENDES, L. O. R.; PEREIRA, A. L.; PROENÇA, M. C. O que dizem as pesquisas sobre a Resolução de Problemas na formação inicial de professores de Matemática: um olhar sobre as fragilidades metodológicas. Educação Matemática Pesquisa, São Paulo, v. 22, n. 2, 27 ago. 2020. DOI: https://doi.org/10.23925/1983-3156.2020v22i2p721-750.

MENDES, L. O. R.; PROENÇA, M. C. O ensino de matemática via Resolução de Problemas na formação inicial de professores. Revista de Educação Matemática, Guarulhos, v. 17, p. e020014, 1 maio 2020. Disponível em: https://www.revistasbemsp.com.br/index.php/REMatSP/article/view/255. Acesso em: 27 dez. 2021.

ONUCHIC, L. R.; ALLEVATO, N. S. G.; NOGUTI, F. C. H.; JUSTULIN, A. M. (org). Resolução de Problemas: Teoria e Prática. Jundiaí, SP: Paco Editorial, 2014.

ONUCHIC, Lourdes de la Rosa; ALLEVATO, Norma Suely Gomes. Pesquisa em Resolução de Problemas: caminhos, avanços e novas perspectivas. Bolema: Mathematics Education Bulletin, Rio Claro, v. 25, n. 41, p. 73-98, 2011. Disponível em: http://hdl.handle.net/11449/72994. Acesso em: 27 dez. 2021.

POLYA, G. A arte de resolver problemas. v. 2. Rio de Janeiro: Interciência, 1994. p. 12.

PROENÇA, M. C. Generalização de padrões algébricos no ensino via Resolução de Problemas: compreensão de licenciandos em Matemática. Educação Matemática Pesquisa, São Paulo, v. 21, n. 3, p. 419-437, 20 dez. 2019a. DOI: https://doi.org/10.23925/1983-3156.2019vol21i3p419$\underline{437}$.

PROENÇA, M. C. Resolução de problemas: encaminhamentos para o ensino e a aprendizagem de Matemática em sala de aula. Maringá: Eduem, 2018.

PROENÇA, M. C. Uma Proposta de Ensino-Aprendizagem das Operações Aritméticas com Frações via Resolução de Problemas. Educação Matemática em Revista, Brasília, v. 24, n. 63, p. 5-17, 21 out. 2019b. Disponível em:

http://sbem.iuri0094.hospedagemdesites.ws/revista/index.php/emr/article/view/1632. Acesso em: 27 dez. 2021.

SOUSA, A. C.; PROENÇA, M. C. Uma proposta de ensino de equação de $1 .^{\circ}$ grau com uma incógnita via Resolução de Problemas. Revista Prática Docente, Confresa, v. 4, n. 2, p. 431-451, 2019. DOI: https://doi.org/10.23926/RPD.2526-2149.2019.v4.n2.p431-451.id511.

STEFANI, Amanda; PROENÇA, Marcelo Carlos de. Análise das dificuldades de alunos dos anos finais do ensino fundamental na Resolução de Problemas de perímetro e área. Revista Paranaense de Educação Matemática, Mourão, v. 8, n. 16, p. 97-118, 2019. Disponível em: http://revista.unespar.edu.br/index.php/rpem/article/view/606. Acesso em: 27 dez. 2021.

STERNBERG, Robert J. Psicologia cognitiva. [S. I.]: Piccin, 2000.

WALLAS, G. The art of thought. New York: Harcourt-Brace, 1926.

\section{Agradecimentos}

O primeiro autor agradece à Coordenação de Aperfeiçoamento de Pessoal de Nível Superior e a terceira autora agradece à Fundação Araucária. 